\title{
Controversy in the Classroom
}

\begin{abstract}
Summary
At Glamorgan, we aim to provide a pluralistic account of the physical sciences, recognizing the all-pervasive nature of science within our society. In attempting to account for the various influences brought to bear on both the practice and the dissemination of science, our science modules repeatedly cross the institutionalised boundaries that separate "science" from "history" or "philosophy". So our degrees (Bsc Science and Science Fiction; Bsc Astronomy and Space; and Bsc Science and Science Communication) are courses about science as much as they are courses in science, encompassing the many influences brought to bear on the continuous creation and consumption of science.
\end{abstract}

Subject Area: Astronomy, Physics, Science Fiction and Science Communication

Science fiction was described by Isaac Asimov as that genre "that deals with the response of human beings to changes in science." It is this response of human beings and society to science as a whole that we examine in the degree programmes we run at Glamorgan: Bsc Science \& Science Fiction; Bsc Astronomy \& Space; and Bsc Science and Science Communication.

The degree courses arose from the development of an astronomy undergraduate programme that provides a pluralistic account of the physical sciences, recognizing the all-pervasive nature of science within our society. We attempted to account for the multifarious influences brought to bear on the nature and dissemination of science; this inevitably led to our science modules repeatedly crossing the institutionalised boundaries that separate "science" from "history" or "philosophy". So our degrees are courses about science as much as they are courses in science, since they encompass the many influences brought to bear on the continuous creation and consumption of science.

The courses make clear the actual, tortuous history of science: its great discoveries, the misapprehensions, and regular stubborn refusals by its practitioners to change course. By teaching not only the findings and products of science, but also communicating its critical method, we hope to better equip academics and science educators with the tools to increase public awareness of, and involvement in science, and provide opportunities for extending science's public franchise.

Since the evolution of science is a complex process, we thought that an interesting way to study it would be to draw upon related disciplines. Traditional scientific accounts are perhaps inhibited from looking at the nature of the links between science and other areas, and their influence upon the growth and dissemination of science. We therefore considered it a natural progression to look at the relationship between science and science fiction.

So just what is science fiction? Perhaps we should start by making it clear that we recognise the complex nature of SF, and are not naive enough to fix SF as merely literary. 
Science fiction is identifiable by the fact that it eases the 'willing suspension of disbelief' on the part of its audience by using an atmosphere of scientific credibility for its imaginative speculations in physical science, space, time, social science, and philosophy.

So science fiction is, in relation to science, a unique genre. It can be regarded as a device for conducting a type of theoretical science - the exploration of imagined worlds. A cosmologist may construct mathematical models of idealised hypothetical universes, and then investigate their properties. Science fiction has more scope. Science fact is supposed to stay within the boundaries of the accepted laws of physics; science fiction may often stray beyond such limits. Nevertheless, the spirit of "What if...?" pervades both enterprises.

The genre has always been used as a way of imagining the relationship between science, technology and society, both as an inspirational source guiding the direction of scientific development and a way of popularising and disseminating scientific ideas. The best science fiction tackles deep philosophical or ethical issues and widens the audience's vision of our universe. Works such as The Time Machine, Brave New World, Yevgeny Zamyatin's We, A Clockwork Orange, Blade Runner and The Matrix. A number of significant individuals stand out in the history of SF - HG Wells and Arthur C Clarke, of course. But also writers such as Philip K Dick, Kurt Vonnegut and William Gibson.

At each stage of the degree we look at what we call the 'seminal milestones of science', and consider their corollary within science fiction. We look at the social and scientific revolutions engendered by the Copernican and Darwinian revolutions, and go on to consider the implications of the twentieth century paradigm shift produced by relativity and quantum theory.

To tease out just a few of the themes that run through the course, in the third year module 'Life in The Universe' we consider Copernicus reluctantly setting in train the eventual development of modern cosmology with its attendant possibility of a plurality of inhabited worlds. Coupled with Darwin's demotion of man to mere mortal among the microbes, we've seen the development of possibly the most powerful myth that has captured the imagination in the latter half of the twentieth century: The myth of the existence of extraterrestrial life. The question of whether we are alone in the cosmos has, of course, fascinated and frightened us since the days of Lucretius.

However, only in recent times has the question of extraterrestrial life become such an obsession; and yet clearly this is almost entirely a revolution of the imagination. The true extraterrestrial with its own physical and mental characteristics begins to appear only in the last third of C19th. The birth of the alien in literature is closely tied to developments in late $\mathrm{C} 19$ th science, most notably evolutionary theory, but also astronomy and the 'plurality of worlds' tradition.

Another module, 'Stars, Science and The Bomb', looks at the development of one of the triumphs of modern physics: the understanding of the stellar life cycle. But in parallel to this study, we consider the development of the atom and hydrogen bombs, finding that in many cases the players in both dramas were the same physicists. This 
enables us to tackle major issues relating to science and social change. It also provides a perfect social and scientific backdrop to our consideration of post-apocalyptic fiction in our 'Utopian and Dystopian Futures' module.

The common theme of all our modules is that of the impact of science throughout history, on all areas of life. The founding principle of all our degrees is our belief that in order to understand and enjoy science, it needs to be made relevant. Physics can be regarded as the marker by which we can trace paradigm shifts throughout the ages, and it is the exciting ways in which this impacts in history, art, and fiction that we use to bring science to life.

Our approach to teaching and learning science has always intended to broaden the franchise both for science and for higher education in general. In recent years there has been an explosive growth in the number of students entering higher education, with an increasing proportion of these young people uninterested in studying specialist degrees.

If we are to attract students to science-based courses perhaps we need to recognise that they may wish to study a diet of science, perhaps acquire a degree of scientific literacy. In our view, knowledge of science is absolutely necessary in a participatory democracy. We live in a society utterly dependent on science and high technology; science itself implies social \& economic change and such change requires a string of vital decisions. As Carl Sagan asks 'How can a citizen with little or no understanding of science be an informed decision-maker in such a society?'

In support of this, potential students are drawn from a wide mix of backgrounds, including both sciences and arts, though a fascination with the nature and communication of scientific ideas is a common drive. We have had great success with the degree both on campus and, just as importantly, in the local valley communities. We have around 100 students taking our cross-disciplinary science modules at the University, and over 200 associate students enrolled on modules of the degree in one of our many local study centres.

As well as students following one of our full degree programmes, we have many major, minor, joint and combined honours students. Students find that an understanding of the historical and cultural impact of science on society, or conversely, the societal and humanistic context of science, can enrich and deepen their understanding of other, narrower disciplines. Students are also encouraged to submit work that incorporates and relates their other studies to the material learnt on our courses - essay titles have included 'The Symbolism of Comets in Art', 'Space Law', 'Cosmic Influences on The Dark Ages?' and 'Evidence For Design?'.

We have implemented continuous assessment, where students give individual and group presentations (on topics such as 'Is Cosmology a Science?', 'Did The Americans Land on the Moon?' and 'Is There Life Beyond The Earth?'), write book reviews and articles, run seminars and submit essays. This is aimed primarily at producing graduates with a broad understanding of science, its method, its impact on society, and the influences of society on science itself. We emphasise a critical approach, encouraging students to be independent thinkers, and trying to combat the doctrinal, unquestioning acceptance of science as it is so often taught in schools. 
New Directions in the Teaching of Physical Sciences

We also address issues relating to the status of science itself: Why is science often considered culturally inferior to the arts? Why is science rarely appreciated as a cultural activity at all? If science is to be restored to its rightful place in our cultural heritage then science fiction may help to play an important part in bringing science "...out of the laboratory and into the culture." Science has become far too important on both local and global scales to be left to the concern of scientists alone.

\section{Author(s)}

Rosi Thornton

Professor Mark Brake

\section{Contact details}

Rosi Thornton

Professor Mark Brake

Centre for Astronomy \& Science Education (CASE)

School of Applied Sciences

University of Glamorgan

Pontypridd

CF37 1DL

rthornto@glam.ac.uk

mbrake@glam.ac.uk 